\title{
SURVEY OF PARTICIPATION IN ORGANISED CERVICAL CANCER-SCREENING PROGRAMME IN HUNGARY
}

\author{
Anikó Gyulai ${ }^{1}$, Attila Nagy², Vera Pataki ${ }^{3}$, Dóra Tonté2 ${ }^{2}$, Róza Ádány², Zoltán Vokó² \\ ${ }^{1}$ Department of Public Health, Faculty of Health, Medical and Health Science Centre, University of Debrecen, Debrecen, Hungary \\ ${ }^{2}$ Department of Preventive Medicine, Faculty of Public Health, Medical and Health Science Centre, University of Debrecen, Debrecen, Hungary \\ ${ }^{3}$ GlaxoSmithKline Hungary, Budapest, Hungary
}

\section{SUMMARY}

Aim: Cervical cancer mortality is high in Hungary, with more than 400 deaths per annum. In 2003, a national cervical cancer screening programme was launched to provide screening services for women who otherwise would not use services themselves. The aim of this survey was to study the socioeconomic and lifestyle factors related to participation in the organised cervical cancer screening programme.

Methods: A questionnaire-based health survey was conducted using a representative sample of women from 25-65 years of age in $11 \mathrm{Hungarian}$ counties. A logistic regression analysis was used to study the association between participation in the screening programme and socioeconomic and lifestyle factors.

Results: $74 \%$ (95\% Cl: $70-77 \%$ ) of the target population underwent a screening examination within the previous three years. Only $15 \%$ (95\% $\mathrm{Cl}: 5-35 \%)$ of the women, who received an invitation letter and took part in the organised screening programme, had never been previously examined by gynaecologist. The participation rates decreased significantly $(p<0.05)$ for those subjects aged $>44$ years, retired, participants with low income, living in small settlements, and reported to be heavy smokers.

Conclusion: Although the overall proportion of Hungary's population that undergoes regular screening for cervical cancer is not low, the organised national cancer screening programme was ineffective in engaging women not regularly visiting their gynaecologist for examination.

Key words: cervical cancer screening, socioeconomic factors, Hungary

Address for correspondence: Z. Vokó, Department of Health Policy and Health Economics, Institute of Economics, Faculty of Social Sciences, Eötvös Loránd University, Pázmány Pétersétány 1/A, H-1117 Budapest. E-mail: voko@tatk.elte.hu

\section{INTRODUCTION}

The mortality rates associated with cervical cancer are very high in Hungary compared to the average in Western European countries of the European Union (Fig. 1). Four hundred and twenty-six women died of this disease in 2012 in a country with

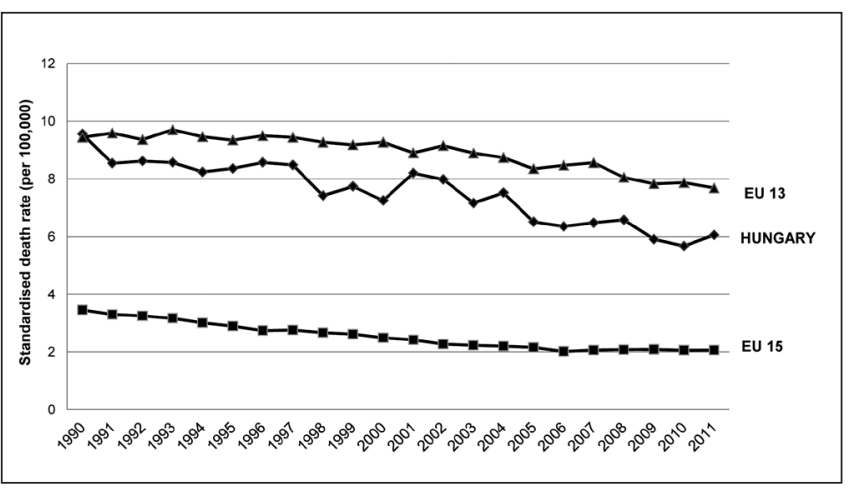

Fig. 1. Cervical cancer mortality in Hungary and EU countries in 1990-2011.

EU15: countries that joined the European Union before 2004; EU 13: countries that joined the European Union since 2004

Source: European Health For All Database (HFA-DB) World Health Organization Regional Office for Europe, Updated January 2014. Standard population: European Old Standard Population. a female population of 5.2 million (1). Opportunistic complex gynaecological screenings (including colposcopic screenings) and cytologic examination with Papanicolau smears have a long tradition in Hungary (2). However, such traditions do not translate to decreased cervical cancer mortality rates. Therefore, a national-level call-and-recall-based organised cervical cancer screening programme was initiated in 2003 in Hungary (3). Women from 25-65 years of age are called for screening every three years by the National Public Health Service in accord with international guidelines (4-6). However, the national cervical cancer screening programme increased the proportion of women who underwent screening by only a few percentage points. Specifically, after the first cycle of organised screenings in $2003-2005$, the proportion increased only slightly from $48.9 \%$ to $52.6 \%$ compared to the reference period (2000-2002), when only opportunistic screening services were available (7-8). Participation in a screening programme is closely related to socioeconomic factors, cultural factors and attitude (9). Reliable information about the attitudes and behaviours of the target population is essential in identifying obstacles to a national cervical cancer screening programme. The aim of our study was to examine socioeconomic and lifestyle factors related to participation in the organised cervical cancer screening programme, to explore the reasons for non-participation and to develop proposals how to overcome these obstacles. 


\section{MATERIALS AND METHODS}

This study was performed in 2008 within the framework of the General Practitioners Morbidity Sentinel Station Programme (GPMSSP). GPMSSP is the first representative chronic disease morbidity monitoring programme in Hungary (10). More than 200 general practitioners from 11 counties report the occurrence of non-communicable diseases with major public health importance via a quality management system. In addition to continuous monitoring, the programme provides a research framework for epidemiological and health services research. The study was approved by the Ethics Committee of the University of Debrecen.

\section{Participants}

The target population included 59,730 women from 11 counties, aged 25-65 years, who are patients of 96 general practitioners' offices that participated in our survey. A total of 3,306 women were selected from the target population by age-stratified random sampling.

\section{Data Collection}

A questionnaire containing questions regarding demographic and socioeconomic factors, health status, lifestyle (including physical activity, diet, smoking, and sexual activity), knowledge about cervical cancer, utilisation of gynaecological services and participation in the cervical cancer screening programme was developed. The questionnaire was tested in focus groups and was further developed before being used in our study. Completing the questionnaire took approximately 25 minutes. The questionnaires along with letters containing instructions were delivered to all participants through their general practitioners' office. The questionnaires were answered anonymously.

\section{Statistical Analysis}

We estimated the frequencies of different characteristics in the target population by weighting the age distribution of the counties to correct for refusal. Marital status was categorised as living with or without a partner. The mean household equivalent monthly income was calculated as the mean total household income per month divided by the square root of the number of persons in household. This adjustment was necessary because the income required to provide the same living standard generally does not increase linearly with the number of people living in the household. Households were divided into quartiles based on their mean household equivalent monthly incomes in Euros $(<281,282-398$, 389-507 and > 508). Settlement size consisted of four categories: municipal towns (largest cities), towns with a population of more than 10,000 but without county rights, towns with a population between 1,000-9,999 and settlements with a population of less than 1,000. Smoking habits were categorised as non-smokers, fewer than 20 cigarettes a day and 20 or more cigarettes a day (heavy smokers). Physical activity was dichotomised into less than 150 minutes per week and at least 150 minutes per week. The body mass index (BMI) was classified according to the recommendations of the World Health Organization as underweight $<18.5$ $\mathrm{kg} / \mathrm{m}^{2}$, normal weight $18.5-24.99 \mathrm{~kg} / \mathrm{m}^{2}$, overweight $25-29.99$
Table 1. Demographic, socioeconomic and lifestyle characteristics of target population $(N=3,306)$

\begin{tabular}{|c|c|}
\hline & Percent $(95 \% \mathrm{Cl})$ \\
\hline \multicolumn{2}{|l|}{ Age (years) } \\
\hline $25-34$ & $26(23-30)$ \\
\hline $35-44$ & $23(20-26)$ \\
\hline $45-54$ & $27(24-30)$ \\
\hline $55-65$ & $24(21-27)$ \\
\hline \multicolumn{2}{|l|}{ Marital status } \\
\hline Not living with a partner & $24(21-27)$ \\
\hline Living with a partner & $76(73-79)$ \\
\hline \multicolumn{2}{|l|}{ Education } \\
\hline Primary education & $21(18-24)$ \\
\hline Secondary education without final examination & $21(18-25)$ \\
\hline Secondary education with final examination & $30(26-33)$ \\
\hline Post-secondary education without diploma & $10(8-13)$ \\
\hline College or university degree & $18(15-21)$ \\
\hline \multicolumn{2}{|l|}{ Mean household equivalent income $(€)^{*}$} \\
\hline$<281$ & $30(26-33)$ \\
\hline $282-398$ & $29(25-33)$ \\
\hline $389-507$ & $21(18-24)$ \\
\hline$>508$ & $21(18-24)$ \\
\hline
\end{tabular}

${ }^{*}$ These quartiles were created for the sample. The uneven distribution of the subjects in the categories is due to weighting.

$\mathrm{kg} / \mathrm{m}^{2}$, and obese $\geq 30 \mathrm{~kg} / \mathrm{m}^{2}$. Sexual activity was characterised by the number of sexual partners within the year preceding the survey. Associations were studied by multiple logistic regression analyses to estimate how strongly the different demographic, socioeconomic and lifestyle factors were related to participation in cervical cancer screening. The reasons why women did not utilise this service were also studied. The survey analysis module of the statistical package STATA was used for the analysis (11).

\section{RESULTS}

Of the 3,306 questionnaires that were sent out, 1,539 (47\%) were returned to the research centre. Table 1 shows the demographic, socioeconomic and lifestyle characteristics of the target population based on the weighted analysis.

After adjustment for the factors, we found that cervical cancer screening participation was significantly $(p<0.05)$ decreased in participants aged 45 years or older. In contrast, higher income was significantly associated with increased participation (Table 2 ), with those women in the highest quartile displaying almost four times greater odds of participating in screening (odds ratio (OR): 3.76, 95\% confidence interval (95\% CI): 1.86-7.61) compared to those in the lowest income category. Women living in settlements with populations less than 10,000 had a $40 \%$ lower probability of partaking in the screening than women living in municipal towns. Heavy smokers had a much lower probability of participating in the screening than non-smokers (OR: $0.39,95 \%$ CI: $0.20-0.78)$. Of the $25-65$ years old women, $35.5 \%$ (95\% CI: $32.9-37.7 \%$ ) received invitation letters for the organised cervi- 
Table 2. Associations between screening participation and various demographic, socioeconomic and lifestyle factors

\begin{tabular}{|c|c|c|c|c|}
\hline Determinants & $\begin{array}{c}\text { Participation in cervical } \\
\text { cancer screening in the } \\
\text { previous three years } \\
\text { percent }(95 \% \mathrm{Cl})\end{array}$ & $\begin{array}{l}\text { Crude odds ratio } \\
\text { percent }(95 \% \mathrm{Cl})\end{array}$ & $\begin{array}{l}\text { Adjusted odds ratio* } \\
\text { percent }(95 \% \mathrm{Cl})\end{array}$ & $\mathrm{p}$-value \\
\hline \multicolumn{5}{|c|}{ Demographic and socioeconomic factors } \\
\hline \multicolumn{5}{|l|}{ Age (years) } \\
\hline $25-34$ & $81(73-87)$ & reference & reference & \\
\hline $35-44$ & $83(77-88)$ & $1.1(0.64-2.1)$ & $0.87(0.42-1.8)$ & 0.7 \\
\hline $45-54$ & $71(65-77)$ & $0.57(0.33-0.99)$ & $0.39(0.19-0.82)$ & 0.01 \\
\hline $55-65$ & $59(52-66)$ & $0.34(0.20-0.58)$ & $0.33(0.14-0.78)$ & 0.01 \\
\hline \multicolumn{5}{|l|}{ Marital status } \\
\hline Not living with a partner & $63(55-70)$ & reference & reference & \\
\hline Living with a partner & $77(74-81)$ & $2.0(1.4-2.9)$ & $1.18(0.68-2.04)$ & 0.56 \\
\hline \multicolumn{5}{|l|}{ Education } \\
\hline Primary education & $54(46-62)$ & reference & reference & \\
\hline Secondary education without final examination & $73(65-80)$ & $2.33(1.41-3.84)$ & $1.46(0.77-2.75)$ & 0.24 \\
\hline Secondary education with final examination & $80(73-85)$ & $3.29(2.0-5.3)$ & $1.47(0.78-2.77)$ & 0.23 \\
\hline Post-secondary education without diploma & $72(61-81)$ & $2.21(1.20-4.09)$ & $0.86(0.41-1.81)$ & 0.70 \\
\hline College or university degree & $87(80-92)$ & $5.83(3.17-10.74)$ & $1.55(0.67-3.56)$ & 0.30 \\
\hline \multicolumn{5}{|l|}{ Mean household equivalent income $(€)$} \\
\hline$<281$ & $62(55-69)$ & reference & reference & \\
\hline 282-398 & $78(72-83)$ & $2.16(1.38-3.40)$ & $2.13(1.19-3.80)$ & 0.01 \\
\hline $389-507$ & $73(65-80)$ & $1.68(1.02-2.77)$ & $1.93(1.08-3.44)$ & 0.03 \\
\hline$>508$ & 88 (82-92) & $4.34(2.54-7.44)$ & $3.76(1.86-7.61)$ & $<10^{-3}$ \\
\hline \multicolumn{5}{|l|}{ Employment } \\
\hline Work or study & $80(76-84)$ & reference & reference & \\
\hline Social welfare & $74(63-83)$ & $0.72(0.41-1.27)$ & $0.79(0.38-1.65)$ & 0.54 \\
\hline Unemployed & $69(51-83)$ & $0.57(0.25-1.26)$ & $0.68(0.29-1.61)$ & 0.34 \\
\hline Retired & $52(42-62)$ & $0.27(0.17-0.43)$ & $0.41(0.20-0.84)$ & 0.02 \\
\hline Disability pensioner & $66(54-76)$ & $0.48(0.27-0.85)$ & $1.17(0.55-2.51)$ & 0.68 \\
\hline Other & $65(43-82)$ & $0.47(0.18-1.20)$ & $0.34(0.09-1.28)$ & 0.11 \\
\hline \multicolumn{5}{|c|}{ Lifestyle factors } \\
\hline \multicolumn{5}{|l|}{ Smoking habits } \\
\hline Non-smoker & $76(72-80)$ & reference & reference & \\
\hline$\geq 20$ cigarettes/day & $73(65-80)$ & $0.85(0.55-1.31)$ & $0.67(0.40-1.13)$ & 0.13 \\
\hline$<20$ cigarettes/day & $60(46-72)$ & $0.46(0.25-0.84)$ & $0.39(0.20-0.78)$ & 0.01 \\
\hline \multicolumn{5}{|l|}{ Physical activity } \\
\hline$<150$ minutes/week & $78(72-83)$ & reference & reference & \\
\hline$\geq 150$ minutes/week & $72(67-76)$ & $0.71(0.49-1.02)$ & $0.75(0.48-1.20)$ & 0.23 \\
\hline \multicolumn{5}{|l|}{ BMI } \\
\hline Underweight & $76(56-89)$ & reference & reference & \\
\hline Normal weight & $76(71-81)$ & $0.99(0.38-2.62)$ & $1.42(0.54-3.78)$ & 0.48 \\
\hline Overweight & $71(65-76)$ & $0.76(0.29-2.0)$ & $1.20(0.45-3.22)$ & 0.72 \\
\hline Obese & $73(66-79)$ & $0.84(0.32-2.25)$ & $1.60(0.58-4.39)$ & 0.37 \\
\hline \multicolumn{5}{|l|}{ Number of sexual partners in the past 12 months } \\
\hline 0 & $53(45-61)$ & reference & reference & \\
\hline 1 & $80(76-83)$ & $3.5(2.4-5.13)$ & $1.58(0.89-2.82)$ & 0.12 \\
\hline$>1$ & 74 (71-77) & $1.76(0.64-4.81)$ & $1.09(0.35-3.38)$ & 0.88 \\
\hline
\end{tabular}

${ }^{*}$ Adjusted for all other factors 
Table 3. Reasons for not participating in the cervical cancer-screening programme among invited women

\begin{tabular}{|l|c|}
\hline Reasons & $\begin{array}{c}\text { Answers }{ }^{*} \text { mentioned } \\
\text { percent (95\% Cl) }\end{array}$ \\
\hline I regularly visit the gynaecologist, who performs this examination & $27(19-35)$ \\
\hline I do not have any problems, so I do not visit a gynaecologist & $23(16-30)$ \\
\hline I could not find time for an appointment & $13(8-18)$ \\
\hline I am afraid of the results of the examination & $12(7-16)$ \\
\hline I had a gynaecological operation earlier, so I no longer need to participate in such an examination & $12(7-17)$ \\
\hline I am afraid of this examination & $9(5-14)$ \\
\hline Other reasons & $4(1-7)$ \\
\hline I had bad experiences in the past & $4(1-7)$ \\
\hline I did not think it was necessary to participate & $3(0.7-6)$ \\
\hline I would need to travel a long distance for this examination & $2(0-4)$ \\
\hline I lack knowledge about this examination & $2(0.2-5)$ \\
\hline I do not want to participate in this gynaecological examination & $2(0.5-5)$ \\
\hline
\end{tabular}

${ }^{*}$ More than one answer may be selected

cal cancer screening. Women who had a registered cytological examination at the National Health Fund in the previous three years were not invited. Only half (53.6\%, 95\% CI: 49.4-57.8\%) of the invited women participated. Of those women who had never had a cytological examination, only $15 \%$ (95\% CI: 5-35\%) took part in the screening even after receiving the invitation letter. Among women who had not visited a gynaecologist within the previous two years, this value was $32 \%$ (95\% CI: $23-43 \%)$. On the contrary, $80 \%$ (95\% CI: $70-8 \%$ ) of women who visited their gynaecologist every year accepted the invitation. The main reason for refusing to participate in organised screening, stated by $27 \%$ (95\% CI: $19-35 \%$ ) of those who provided a reason, was that they regularly visited their gynaecologist i.e. these women participated in opportunistic screening (Table 3). The lack of gynaecological complaints and fear of the examination results as well as the examination itself were also often mentioned as reasons for refusal.

\section{DISCUSSION}

Today, most European countries conduct organised public health screening programmes to prevent cervical cancer, although they differ in organisation, management and efficiency (12-14). In countries where organised public health screening has been introduced, the coverage generally increases, and the main reasons for non-attendance are low socioeconomic status and cultural obstruction (15-16). According to our survey, the overall screening rate in Hungary (74\%) is not low. The real frequency, however, is likely to be lower because of the selection bias associated with a relatively low response rate of $47 \%$. To decrease the effect of this bias, we applied weighted estimations by age and county. Nevertheless, it is reasonable to assume that the level of health consciousness was, on average, higher among the respondents than in the target population.

Organised screening resulted in only minimal increases in cervical cancer screening coverage rates in Hungary (7). Although the organised screenings began in 2003, the number of sample tests conducted outside the programme is still 20 times higher than within the screening programme (17-18). In agreement with this finding, our main result indicated that the vast majority of those women who do not visit their gynaecologist regularly still refused participation in the organised screening programme. Lower socioeconomic status and unhealthy behaviours were associated with non-participation.

According to findings from other countries, higher education increases participation in those countries where opportunistic screening is prevalent. The same relationship is not evident in countries with organised public health screenings (19).

There are different practices across European countries as to the health professionals collecting the cervical smear. In certain Western European countries, either general practitioners in primary health settings (Denmark and the Netherlands) or nurses and midwives (Finland, Sweden and the UK) collect the smear (4). In Hungary, because of the tradition of opportunistic screenings, only gynaecologists can collect the smear (20). The screening test includes not only cytological examinations but colposcopic examinations as well. Thus, the examinations often occur only in outpatient service settings in larger population centres, which limit accessibility for village dwellers.

Effective communication is a key success factor for an organised screening programme (21). The inefficiency of screening is reflected in the finding that many women were still afraid of the examination itself or of the examination result, while some thought that screening was unnecessary if they did not have any gynaecological complaints.

When developing a screening programme, it is important to increase its accessibility, especially for low-income families and gypsies (22-25). If a smear could be collected in primary healthcare settings by general practitioners, nurses or public health nurses (as a standard practice in several Western European countries), participation rates in Hungary would most likely increase. Primary health care services are more accessible than gynaecologists to the general population. The staff of primary health care centres is familiar with the cultural and socioeconomic background of the local population and could also be involved in local communication efforts regarding the programme. In 2009, a model programme involving 110 public health nurses from 168 small settlements was launched by the Office of the Chief Medical Officer. After three months training, the public health nurses 
collected smears from 4,764 (34.5\%) women of 13,823 invitees with no history of screenings in the previous three years.

While the proportion of Hungary's total population that undergoes screening for cervical cancer is not low, the national organised screening programme was not successful in encouraging participation in those women who do not visit their gynaecologists regularly, have low socioeconomic status, live in small settlements, are older than 45, or are heavy smokers. Effective health communication, education and promotion are needed to empower women to increase participation in a screening programme. Considering the characteristics and needs of the target population are essential elements for improving the design of the national cervical screening programme.

\section{Acknowledgements}

We would like to thank the general practitioners involved in the study.

\section{Funding}

The work was supported by a grant from the National Research and Development Program (NKFP-1/0003/2005).

\section{Ethical Approval}

The study was approved by the Ethics Committee of the University of Debrecen.

\section{Declaration of Authorship:}

AGY, AN, RÁ, VP and ZV conceptualized the study and led the design. $\mathrm{AGY}$ and $\mathrm{ZV}$ were involved in data analysis, presentation and interpretation of the results, and drafting the first and final version of the article. NA and DT were involved in data analysis, presentation and interpretation of the results. All authors critically revised the article for important intellectual content and approved the final draft.

\section{Conflict of Interests}

VP is a full-time employee of GlaxoSmithKline Ltd., which has a financial interest related to the prevention of cervical cancer as the producer of a human papillomavirus vaccine. $\mathrm{ZV}$ regularly provided consultancy service for GlaxoSmithKline Hungary Ltd. as the member of its advisory board on vaccination, and received funding for other research from the company.

\section{REFERENCES}

1. Hungarian Central Statistical Office. Demographic yearbook 2012. Budapest: Hungarian Central Statistical Office; 2013.

2. Döbrössy L. Five decades of cervical cancer screening in Hungary. Nögyógyászati Onkológia. 2007;12(1):5-9. (In Hungarian.)

3. Kovacs A, Döbrössy L, Budai A, Boncz I, Cornides A. The state of organized cervical screening program in Hungary in 2006. Orv Hetil. 2007 Mar 25;148(12):535-40. (In Hungarian.)

4. Arbyn M, Anttila A, Jordan J, Ronco G, Schenck U, Segnan N, et al. editors. European guidelines for quality assurance in cervical cancer screening. 2nd ed. Luxembourg: Office for Official Publications of the European Communities; 2008.

5. IARC Working Group on Cervical Cancer Screening and the UICC Project Group on the Evaluation of Screening Programmes for Cancer. Screening for cancer of the uterine cervix. IARC Sci Publ. 1986;(76):1-315.
6. International Agency for Research on Cancer. Cervix cancer screening. IARC/WHO Handbooks of cancer prevention, vol. 10. Lyon: IARC; 2005.

7. Boncz I, Sebestyén A, Döbrössy L, Kovács A, Budai A, Székely T. The coverage of cervical screening in Hungary. Orv Hetil. 2007 Nov 18;148(46):2177-82. (In Hungarian.)

8. Kovács A, Boncz I. The state of the organized oncological screening in Hungary. Népegészségügy. 2009;87(4):265-74. (In Hungarian.)

9. Akers AY, Newmann SJ, Smith JS. Factors underlying disparities in cervical cancer incidence, screening, and treatment in the United States. Curr Probl Cancer. 2007 May-Jun;31(3):157-81.

10. Széles G, Vokó Z, Jenei T, Kardos L, Pocsai Z, Bajtay A, et al. A preliminary evaluation of a health monitoring programme in Hungary. Eur J Public Health. 2005 Feb;15(1):26-32.

11. StataCorp. Stata statistical software: release 8.2. College Station: StataCorp; 2003.

12. von Karsa L, Anttila A, Ronco G, Ponti A, Malila N, Arbyn M. Cancer screening in the European Union: report on the implementation of the Council Recommendation on cancer screening. First Report. Luxembourg: European Communities; 2008.

13. Holland WW, Stewart S, Masseria C. Policy brief screening in Europe. Geneva: WHO; 2006.

14. Anttila A, Ronco G, Clifford G, Bray F, Hakama M, Arbyn M, et al. Cervical cancer screening programmes and policies in 18 European countries. Br J Cancer. 2004 Aug 31;91(5):935-41.

15. Arbyn M, Quataert P, Van Hal G, Van Oyen H. Cervical cancer screening in the Flemish region (Belgium): measurement of the attendance rate by telephone interview. Eur J Cancer Prev. 1997 Aug;6(4):389-98.

16. Garner EI. Cervical cancer: disparities in screening, treatment, and survival. Cancer Epidemiol Biomarkers Prev. 2003 Mar;12(3):242-7.

17. Kovács A, Döbrössy L, Budai A, Boncz I, Cornides A. Cervical screening in Hungary: why does the "English model" work but the "Hungarian model" does not? Eur J Gynaecol Oncol. 2008;29(1):5-9.

18. Anttila A, Ronco G; Working Group on the Registration and Monitoring of Cervical Cancer Screening Programmes in the European Union; within the European Network for Information on Cancer (EUNICE). Description of the national situation of cervical cancer screening in the member states of the European Union. Eur J Cancer. 2009 Oct;45(15):2685-708.

19. Palència L, Espelt A, Rodríguez-Sanz M, Puigpinós R, Pons-Vigués M, Pasarín MI, et al. Socio-economic inequalities in breast and cervical cancer screening practices in Europe: influence of the type of screening program. Int J Epidemiol. 2010 Jun;39(3):757-65.

20. Döbrössy L, editor. Organized oncology screening programs: a quality assurance handbook and methodological guideline. Budapest: Egészségügyi Minisztérium; 2000. (In Hungarian.)

21. Giordano L, Webster P, Anthony C, Szarewski A, Davies P, Arbyn M, et al. Improving the quality of communication in organised cervical cancer screening programmes. Patient Educ Couns. 2008 Jul;72(1):130-6.

22. Weller DP, Campbell C. Uptake in cancer screening programmes: a priority in cancer control. Br J Cancer. 2009 Dec 3;101 Suppl 2:S55-9.

23. Weller DP, Patnick J, McIntosh HM, Dietrich AJ. Uptake in cancer screening programmes. Lancet Oncol. 2009 Jul;10(7):693-9.

24. Baron RC, Rimer BK, Coates RJ, Kerner J, Kalra GP, Melillo S, et al.; Task Force on Community Preventive Services. Client-directed interventions to increase community access to breast, cervical, and colorectal cancer screening a systematic review. Am J Prev Med. 2008 Jul;35(1 Suppl):S56-66.

25. Spadea T, Bellini S, Kunst A, Stirbu I, Costa G. The impact of interventions to improve attendance in female cancer screening among lower socioeconomic groups: a review. Prev Med. 2010 Apr;50(4):159-64. 